\title{
Analysis of risk factors of PICC-related bloodstream infection in newborns: implications for nursing care
}

Yan Hu, Yun Ling ${ }^{*}$, Yingying Ye, Lu Zhang, Xiaojing Xia, Qianwen Jiang and Fang Sun

\begin{abstract}
Background: It is necessary to analyze the characteristics and risk factors of catheter-related bloodstream infection (CRBSI) in newborns with peripherally inserted central catheter (PICC).

Methods: Newborns undergoing PICC catheterization in the neonatal department of our hospital from January 1 , 2020 to January 31, 2021 were included. The characteristics of newborns with and without CRBSI newborns were compared and analyzed. Logistic regression analyses were performed to evaluate the risk factors of CRBSI in newborns with PICC.

Results: Three hundred eighty-six newborns with PICC were included, of whom 41 newborns had the CRBSI, the incidence of CRBSI in newborns with PICC was 10.62\%. There were significant differences regarding the birth weight, durations of PICC stay, 5-min Apgar score, site of PICC insertion of PICC between CRBSI and no CRBSI group (all $P<0.05)$, and there were no significant differences regarding the gender, gestational age, cesarean section, mechanical ventilation and length of hospital stay between CRBSI and no CRBSI group (all $P>0.05$ ). Escherichia coli (26.08\%) and Staphylococcus aureus (23.92\%) were the most common CRBSI pathogens in newborns with PICC. Logistic regression analysis indicated that birth weight $\leq 1500 \mathrm{~g}(\mathrm{OR} 1.923,95 \% \mathrm{Cl} 1.135-2.629)$, durations of PICC stay $\geq 21$ days (OR 2.077, 95\% Cl 1.024-3.431), 5-min Apgar score $\leq 7$ (OR 2.198, 95\% Cl 1.135-3.414) and femoral vein insertion of PICC (OR 3.044, 95\% Cl 1.989-4.306) were the independent risk factors of CRBSI in neonates with PICC (all $P<0.05$ ).
\end{abstract}

Conclusion: For newborns with low birth weight, longer durations of PICC stay and femoral vein PICC insertion, they may have higher risks of CRBSI, and medical staff should take targeted measures to reduce the development of CRBSI.

Keywords: Newborns, PICC, CRBSI, Nurse, Care, Management

\section{Background}

Peripherally inserted central catheter (PICC) refers to the use of a catheter to puncture a vein in the peripheral vein, and the catheter goes directly to the large vein near the heart, providing convenience for neonatal fluid infusion. PICC has become an important life channel for neonates especially premature neonates in clinical treatment $[1,2]$.

*Correspondence: iqswi2246086@163.com

Department of Nursing, Children's Hospital, School of Medicine, Zhejiang University, No. 3333 Binsheng Road, Binjiang District, Hangzhou City,

Zhejiang Province, China
The PICC application has the characteristics of simple operation, softness and easy observation [3]. It can stay in the body for a long time without repeated puncture. It provides a better infusion channel for neonatal treatment and is convenient for the infusion of important vasoactive drugs, intravenous nutrient solutions, antibiotics [4]. Therefore, PICC is widely used in neonates, especially premature infants.

Peripherally inserted central catheter is an important way of long-term intravenous infusion or nutritional support for newborns, but it may also have many complications. It has been reported that it is easy to cause catheter original author(s) and the source, provide a link to the Creative Commons licence, and indicate if changes were made. The images or other third party material in this article are included in the article's Creative Commons licence, unless indicated otherwise in a credit line to the material. If material is not included in the article's Creative Commons licence and your intended use is not permitted by statutory regulation or exceeds the permitted use, you will need to obtain permission directly from the copyright holder. To view a copy of this licence, visit http://creativecommons.org/licenses/by/4.0/. The Creative Commons Public Domain Dedication waiver (http://creativeco mmons.org/publicdomain/zero/1.0/) applies to the data made available in this article, unless otherwise stated in a credit line to the data. 
blockage, infection, mechanical phlebitis and other adverse complications due to improper care, of which the most serious one is catheter-related bloodstream infection (CRBSI) [5]. Previous studies [6, 7] have reported that the incidence of CRBSI in NICU varied from 7.25 to $13.78 \%$. CRBSI not only prolongs the hospitalization time of newborns, but also may increase the mortality of newborns [8]. In order for PICC to be better used in newborns, it is very important to properly use cluster nursing interventions to prevent the occurrence of CRBSI. Therefore, we aimed at retrospectively analyzing the characteristics of neonates with PICC, to identify the risk factors of CRBSI in neonates with PICC, thereby providing reliable evidences to the management of PICC in clinical nursing care.

\section{Methods}

\section{Ethical approval}

In this study, all methods were performed in accordance with the relevant guidelines and regulations. Our study had been checked and approved by the ethical committee of medical research of our hospital (Approval Number: NU190128c), and written informed consents had been obtained from the guardians or relatives of included neonates.

\section{Neonates}

We selected newborns who underwent PICC catheterization in the neonatal department of our hospital from January 1, 2020 to January 31, 2021 as the research populations. The inclusion criteria for newborns were as following: (1) newborns younger than 28 days old; (2) PICC insertion was conducted in our department, and no signs of infection such as fever, positive blood culture were found before the catheterization; and (3) the newborn's family members were well informed and signed informed consent. The exclusion criteria for this study were: (1) newborns who underwent PICC insertion in other hospital; (2) newborns who were extubated within $48 \mathrm{~h}$ of PICC insertion; and (3) newborns whose family members refused to participate in this study.

\section{Peripherally inserted central catheter insertion}

In this study, PICC insertions were performed by three PICC specialist nurses who had received professional theory and practice training. We selected $1.9 \mathrm{~F}$ catheter produced by Medical Components, Inc. DBA-Med Company to perform the PICC. The basilic vein was selected as the first choice for PICC puncture site, followed by the median cubital vein, axillary vein, and femoral vein. PICC operators were all personnel who had obtained the PICC specialist qualification certificate with professional training and have been engaged in clinical work. The PICC was placed in a laminar flow condition, and all the PICC insertion was conducted according to related standard procedures. After PICC catheterization, X-rays were used to confirm whether the catheter was in place.

\section{Catheter-related bloodstream infection diagnosis}

The HP/PYP blood culture bottle was used to culture newborn blood samples, BACTEC 9240 blood culture instrument (USA) was used to test newborn blood samples, and the tip of the PICC catheter was placed in the blood agar culture medium (Becton, Dickinson and Company) for cultivation. Strain identification was analyzed with VITEK microbial automatic analyzer RC200 (France BioMérieux). In this study, the CRBSI was defined as the same colony cultured in peripheral blood and the tip of the PICC catheter after $48 \mathrm{~h}$ of catheter placement or within $48 \mathrm{~h}$ of extubation [9].

\section{Data collection}

Two authors independently collected following information with unified forms, including gender, gestational age, birth weight, cesarean section, durations of PICC stay, 5-min Apgar score, mechanical ventilation, site of PICC insertion and the length of hospital stay.

\section{Statistical analysis}

We used SPSS 23.00 software to perform statistical analysis. Measurement data were expressed as mean \pm standard deviation, and comparison between groups was performed by $t$ test. The count data were expressed as the number of cases or percentages, and the Chi-square test was used for comparison between groups. The factors with statistical significance in univariate analysis were further included in multivariate analysis, and related risk factors were analyzed by logistic regression model. In this study, $P \leq 0.05$ was considered as the difference between the groups was statistically significant.

\section{Results}

\section{The characteristics of included newborns}

A total of 386 newborns with PICC were included, of whom 41 newborns had the CRBSI; the incidence of CRBSI in newborns with PICC was $10.62 \%$. As indicated in Table 1, there were significant differences regarding the birth weight, durations of PICC stay, 5-min Apgar score, site of PICC insertion of PICC between CRBSI and no CRBSI group (all $P<0.05$ ), and there were no significant differences regarding the gender, gestational age, cesarean section, mechanical ventilation and length of hospital stay between CRBSI and no CRBSI group (all $P>0.05)$. 
Table 1 The characteristics of included newborns

\begin{tabular}{|c|c|c|c|c|}
\hline Variables & CRBSI group $(n=41)$ & No CRBSI group $(n=345)$ & $t / x^{2}$ & $P$ \\
\hline Gender (male/female) & $24 / 17$ & $211 / 134$ & 1.215 & 0.107 \\
\hline Gestational age (weeks) & $32.10 \pm 4.58$ & $33.04 \pm 2.16$ & 3.108 & 0.075 \\
\hline Birth weight (g) & $1468.82 \pm 212.14$ & $1596.24 \pm 243.92$ & 42.137 & 0.012 \\
\hline Cesarean section & $32(78.05 \%)$ & $260(75.36 \%)$ & 1.196 & 0.088 \\
\hline Durations of PICC stay (days) & $24.18 \pm 3.01$ & $17.29 \pm 3.25$ & 3.122 & 0.031 \\
\hline 5-min Apgar score & $6.14 \pm 2.06$ & $7.83 \pm 2.19$ & 1.287 & 0.024 \\
\hline Mechanical ventilation & $35(85.37 \%)$ & $288(83.48 \%)$ & 1.441 & 0.092 \\
\hline \multicolumn{5}{|l|}{ Site of PICC insertion } \\
\hline Basilic vein & $24(58.54 \%)$ & $257(74.49 \%)$ & 1.326 & 0.014 \\
\hline Cephalic vein & $5(12.19 \%)$ & $32(9.27 \%)$ & & \\
\hline Median elbow vein & $4(9.76 \%)$ & $24(6.96 \%)$ & & \\
\hline Axillary vein & $3(7.32 \%)$ & $17(4.93 \%)$ & & \\
\hline Femoral vein & $5(12.19 \%)$ & $15(4.35 \%)$ & & \\
\hline Length of hospital stay (days) & $36.14 \pm 7.21$ & $35.58 \pm 6.28$ & 3.206 & 0.065 \\
\hline
\end{tabular}

Table 2 Distribution of CRBSI pathogens in neonates with PICC $(n=46)$

\begin{tabular}{lcc}
\hline Pathogens & Number & Proportion (\%) \\
\hline Gram-positive bacteria & 19 & 41.31 \\
Staphylococcus aureus & 11 & 23.92 \\
Hemolytic streptococcus & 5 & 10.87 \\
Staphylococcus epidermidis & 3 & 6.52 \\
Gram-negative bacteria & 24 & 52.17 \\
Escherichia coli & 12 & 26.08 \\
Pseudomonas aeruginosa & 5 & 10.87 \\
Enterobacter cloacae & 3 & 6.52 \\
Klebsiella pneumoniae & 2 & 4.35 \\
Acinetobacter baumannii & 2 & 4.35 \\
Fungus & 3 & 6.52 \\
Candida albicans & 3 & 6.52 \\
\hline
\end{tabular}

\section{Catheter-related bloodstream infection pathogens}

As indicated in Table 2, of the 41 cases of CRBSI, 46 pathogens were detected in the bacteria culture. Escherichia coli $(26.08 \%)$ and Staphylococcus aureus (23.92\%) were the most common CRBSI pathogens in newborns with PICC.

\section{The risk factors of CRBSI in neonates with PICC}

The variable assignment of multivariate logistic regression is presented in Table 3. As indicated in Table 4, logistic regression analysis found that birth weight $\leq 1500 \mathrm{~g}$ (OR 1.923, 95\% CI 1.135-2.629), durations of PICC stay $\geq 21$ days (OR 2.077, 95\% CI 1.024-3.431), 5-min Apgar score $\leq 7$ (OR 2.198, 95\% CI 1.135-3.414) and femoral
Table 3 The variable assignment of multivariate logistic regression

\begin{tabular}{lll}
\hline Factors & Variables & Assignment \\
\hline CRBSI & $Y$ & Yes $=1, \mathrm{no}=2$ \\
Birth weight (g) & $X_{1}$ & $\leq 1500=1,>1500=2$ \\
Durations of PICC stay (days) & $X_{2}$ & $\geq 21=1,<21=2$ \\
5-min Apgar score & $X_{3}$ & $\leq 7=1,>7=2$ \\
Femoral vein insertion of PICC & $X_{4}$ & yes $=1, \mathrm{no}=2$ \\
\hline
\end{tabular}

Table 4 Logistic regression analysis on the risk factors of CRBSI in neonates with PICC

\begin{tabular}{|c|c|c|c|c|c|}
\hline Variables & $\beta$ & $s \bar{x}$ & OR & $95 \% \mathrm{Cl}$ & $P$ \\
\hline Birth weight $\leq 1500 \mathrm{~g}$ & 0.204 & 0.211 & 1.923 & $1.135-2.629$ & 0.022 \\
\hline $\begin{array}{l}\text { Durations of PICC stay } \geq 21 \\
\text { days }\end{array}$ & 0.818 & 0.126 & 2.077 & $1.024-3.431$ & 0.036 \\
\hline 5-min Apgar score $\leq 7$ & 0.421 & 0.117 & 2.198 & $1.135-3.414$ & 0.017 \\
\hline $\begin{array}{l}\text { Femoral vein insertion of } \\
\text { PICC }\end{array}$ & 0.119 & 0.203 & 3.044 & $1.989-4.306$ & 0.009 \\
\hline
\end{tabular}

vein insertion of PICC (OR 3.044, 95\% CI 1.989-4.306) were the independent risk factors of CRBSI in neonates with PICC (all $P<0.05$ ).

\section{Discussion}

One of the most serious complications of PICC is CRBSI, which is associated with a longer length of hospital stay, increased medical costs, and elevated risk of death [10]. Although the current clinical care has been improved in the selection of PICC catheter materials, the qualification 
requirements of puncture personnel, puncture operation procedures and schedule maintenance specifications, CRBSI are still inevitable. Previous studies $[11,12]$ have reported the incidence of PICC-related CRBSI is between 8.11 and $12.35 \%$. The results of this study have shown that the incidence of CRBSI in our department is $10.62 \%$, which is consistent with the results of related studies. Moreover, we have found that birth weight $\leq 1500 \mathrm{~g}$, durations of PICC stay $\geq 21$ days, 5-min Apgar score $\leq 7$ and femoral vein insertion of PICC are the independent risk factors of CRBSI in neonates with PICC (all $P<0.05$ ). Clinically, nursing intervention measures should be taken as soon as possible in response to these risk factors to reduce the onset of CRBSI in neonates with PICC.

Neonates have low immunity and poor resistance to infection, and they are a high-risk group of nosocomial infections. PICC placement can increase the risk of nosocomial infections [13]. A multi-center case-control study [14] have showed that after PICC catheterization for more than 2 weeks, the risk of CRBSI continues to increase with the extension of PICC stay. The defense function of newborns with a birth weight of $\leq 1500 \mathrm{~g}$ is imperfect, and newborns with Apgar score $\leq 7$ are in poor physical condition, which will increase the risk of CRBSI $[15,16]$. In response to the above risk factors, nurses should take appropriate measures as much as possible to reduce the occurrence of CRBSI, such as daily assessment of extubation indications, appropriate PICC care.

Previous study [17] has analyzed the bacterial spectrum of CRBSI in 125 hospitals in 26 European countries and found that Gram-positive bacteria accounted for $70.7 \%$, Gram-negative bacteria accounted for $22.2 \%$, and fungi accounted for $7.2 \%$. In this study, Gram-positive cocci accounted for $41.31 \%$, Gram-negative bacilli accounted for $52.17 \%$, and fungi accounted for $6.52 \%$. This is different from previous related reports $[18,19]$. The reason may be related to the strict control of antibiotics use in newborns in our department, and secondly to the hand hygiene of medical staff. The supervision of the department is related to the daily secondary quality control. In recent years, with the strict control of the use of antibacterial drugs in hospitals, the clinical use of antibacterial drugs has become more and more standardized and strict. Effective management of antibacterial drugs reduces the production of drug-resistant bacteria, which has caused changes in the bacterial spectrum of catheter CRBSI in recent years [20]. The preventive use of fluconazole has also greatly reduced the rate of fungal infections [21].

Peripherally inserted central catheter is a tool for intravenous therapy. The qualification declaration and certification process, training and assessment, and qualification access of operating nurses or physicians should comply with the industrial management of intravenous infusion, which is conducive to promoting the professional development of intravenous infusion therapy [22]. The patients who use PICC catheters are mostly children or tumor patients. The elasticity of the blood vessels of those patients is generally poor. At the same time, the anatomical position of the blood vessels of some patients has a certain variation [23]. Therefore, the operator is required to have very skilled technology and rich experience. It has been reported that the experiences of PICC operators may be associated with the CRBSI [24, 25]. Therefore, all PICC operations in the clinic must be performed by personnel with relevant operating qualifications $[26,27]$.

At present, many hospitals do not have clear regulations on the duration of PICC stay. Studies [28, 29] have reported that regular replacement of the catheter does not reduce the risk of CRBSI. Studies [30-32] have reported that in NICU, PICC catheter indwelling time is an independent risk factor for the occurrence of CRBSI. In the first 18 days after PICC catheterization, the incidence of CRBSI increases by $14 \%$ per day, and 19-35 days after catheterization, the incidence of CRBSI will no longer increase, and the incidence of CRBSI will increase by $33 \%$ every day in the $36-60$ days after catheterization. However, studies [33, 34] have also reported that prolonging the indwelling time of PICC catheters does not increase the incidence of CRBSI, which may be related to adequate nutritional support, reduction of other invasive procedures, and increased skin maturity in children. At the same time, studies [35-37] have reported that strict aseptic techniques and careful observation and care are the key to preventing CRBSI. The insertion site of the PICC has a great influence on the risk of CRBSI. The basilic vein is generally straight and thick. When the arms are perpendicular to the torso, basilic vein is the straightest and most direct way. The chances of mechanical phlebitis and ectopic catheterization are the lowest after puncture of the basilic vein, so the basilic vein should be the first choice [38, 39]. Several previous studies [40-42] have pointed that the femoral vein catheterization is prone to blood embolism, thus femoral vein should be avoided for PICC insertion. It must be noted that the data evaluation concerning femoral vein catheters are based on purely 5 incidences in this present study, which is far too low to make any reasonable inferences. Therefore, the data should be interpreted with caution and more studies on this issue are needed in the future.

This study has certain limitations. First, the sample size of this study is small; it may be underpowered to detect the potential risk factors. Secondly, there are many risk factors for CRBSI in newborns with PICC. This study is a retrospective study design and the analyzed factors 
included are limited. The experiences of surgeons or nurses may have significant influences on the PICCrelated infection. In our study, all the three PICC specialist nurses had more than 5 years experience of PICC insertion, limited by the sample size, it may not have power enough to detect the group differences. Other factors such as aseptic operation during puncture and the application of antibiotics during hospitalization may also have an impact on the development of CRBSI [43, 44]. How to prevent the occurrence of CRBSI in newborns with PICC still needs further investigation.

\section{Conclusions}

In conclusion, the incidence of CRBSI in newborns with PICC is rather high, for newborns with birth weight $\leq 1500 \mathrm{~g}$, duration of PICC stay $\geq 21$ days, 5-min Apgar score $\leq 7$ and femoral vein insertion of PICC, they may have higher risks of CRBSI, early preventions and interventions targeted on those risk factors should be implemented. In-depth understanding of the risk factors of neonatal PICC-related CRBSI, mastering clustered nursing intervention measures for the management of PICC is an important guarantee to ensure the smooth completion of neonatal intravenous treatment and the reduction of CRBSI.

\section{Abbreviations \\ CRBSI: Catheter-related bloodstream infection; PICC: Peripherally inserted central catheter.}

\section{Acknowledgements}

None.

\section{Authors' contributions}

$Y H, Y L$ designed research; $Y H, Y L, Y Y, L Z, X X, Q J, F S$ conducted research; $Y H$, $Y Y$ analyzed data; $Y L$ wrote the first draft of manuscript; $Y L, X X$ had primary responsibility for final content. All authors read and approved the final manuscript.

\section{Funding}

None.

\section{Availability of data and materials}

All data generated or analyzed during this study are included in this published article.

\section{Declarations}

\section{Ethics approval and consent to participate}

In this study, all methods were performed in accordance with the relevant guidelines and regulations. Our study had been checked and approved by the ethical committee of medical research of our hospital (Approval Number: NU190128c), and written informed consents had been obtained from the guardians or relatives of included neonates.

\section{Consent for publication}

Not applicable.

\section{Competing interests}

The authors declare that they have no competing interests.
Received: 3 June 2021 Accepted: 6 July 2021

Published online: 23 July 2021

\section{References}

1. Govindan S, Jobe A, O'Malley ME, Flanders SA, Chopra V. To PICC or not to PICC? A cross-sectional survey of vascular access practices in the ICU.J Crit Care. 2021;63:98-103.

2. Gullo G, Colin A, Frossard P, Jouannic AM, Knebel JF, Qanadli SD. Appropriateness of replacing fluoroscopic guidance with ECG-electromagnetic guidance for PICC insertion: a randomized controlled trial. AJR Am J Roentgenol. 2021;216:1-8.

3. Fernandez-Hidalgo N, Almirante B, Calleja R, Ruiz I, Planes AM, Rodriguez D, Pigrau C, Pahissa A. Antibiotic-lock therapy for long-term intravascular catheter-related bacteraemia: results of an open, non-comparative study. J Antimicrob Chemother. 2006;57(6):1172-80.

4. Fakih M, Sturm L. Paving the PICC journey: building structures, process and engagement to improve outcomes. BMJ Qual Saf. 2021. https://doi. org/10.1136/bmjqs-2020-012910.

5. Acun C, Baker A, Brown LS, Iglesia KA, Sisman J. Peripherally inserted central catheter migration in neonates: incidence, timing and risk factors. J Neonatal Perinat Med. 2021. https://doi.org/10.3233/NPM-200684.

6. Mateo-Lobo R, Riveiro J, Vega-Pinero B, Botella-Carretero Jl. Infectious complications in home parenteral nutrition: a systematic review and meta-analysis comparing peripherally-inserted central catheters with other central catheters. Nutrients. 2019;11(9):2083.

7. Ren XL, Li HL, Liu J, Chen YJ, Wang M, Qiu RX. Ultrasound to localize the peripherally inserted central catheter tip position in newborn infants. Am J Perinatol. 2021;38(2):122-5.

8. Brooker RW, Keenan WJ. Catheter related bloodstream infection following PICC removal in preterm infants. J Perinatol. 2007;27(3):171-4.

9. China MoHotPsRo. Hospital infection diagnostic criteria. Chin Med J. 2010;18(2):12-9.

10. Simonetti G, Sommariva A, Lusignani M, Anghileri E, Ricci CB, Eoli M, Fittipaldo AV, Gaviani P, Moreschi C, Togni S, et al. Prospective observational study on the complications and tolerability of a peripherally inserted central catheter (PICC) in neuro-oncological patients. Support Care Cancer. 2020;28(6):2789-95.

11. Inoue S, Yoshida T, Nishino T, Goto M, Nishioka K, Fujimoto K, Aoyama M, Matsumoto D, Takizawa H, Tangoku A. Safe central venous catheters for esophageal cancer treatment. J Med Invest. 2020;67(3.4):298-303.

12. Mariggio E, lori AP, Micozzi A, Chistolini A, Latagliata R, Berneschi P, Giampaoletti M, La Rocca U, Bruzzese A, Barberi W, et al. Peripherally inserted central catheters in allogeneic hematopoietic stem cell transplant recipients. Support Care Cancer. 2020;28(9):4193-9.

13. Gonzalez S, Jimenez P, Saavedra P, Macias D, Loza A, Leon C, Lopez M, Palleja E, Hernandez-Socorro CR, Ruiz-Santana S. Five-year outcome of peripherally inserted central catheters in adults: a separated infectious and thrombotic complications analysis. Infect Control Hosp Epidemiol. 2020. https://doi.org/10.1017/ice.2020.1300.

14. Huifen C. Application of clustered nursing intervention in catheterrelated bloodstream infection in hemodialysis patients. Chongqing Med. 2019;16(1):423-4.

15. Mizusawa M, Vindenes T, Buckley S, Armstrong C. A case series of rapidly growing mycobacterial catheter-related bloodstream infections among immunocompetent patients. J Clin Tuberc Other Mycobact Dis. 2020;21:100196.

16. Piredda A, Radice D, Zencovich C, Cerri M, Aventino L, Naccarato F, Magon G, Biffi R. Safe use of peripherally inserted central catheters for chemotherapy of solid malignancies in adult patients: a 1-year monocentric, prospectively-assessed, unselected cohort of 482 patients. J Vasc Access. 2020. https://doi.org/10.1177/1129729820962905.

17. Bouza E, San Juan R, Munoz P, Pascau J, Voss A, Desco M. Cooperative group of the European study group on nosocomial I: a European perspective on intravascular catheter-related infections: report on the microbiology workload, aetiology and antimicrobial susceptibility (ESGNI005 study). Clin Microbiol Infect. 2004;10(9):838-42.

18. Suzuki D, Kobayashi R, Sano H, Yanagi M, Hori D, Matsushima S, Nakano T, Kobayashi K. Peripherally inserted central venous catheter for pediatric 
and young adult patients with hematologic and malignant diseases. J Pediatr Hematol Oncol. 2020;42(7):429-32.

19. Rossidis AC, Brown EG, Payton KJ, Mattei P. Implementation of an evidence-based protocol after appendectomy reduces unnecessary antibiotics. J Pediatr Surg. 2020;55(11):2379-86.

20. Javeri Y, Jagathkar G, Dixit S, Chaudhary D, Zirpe KG, Mehta Y, Govil D, Mishra RC, Samavedam S, Pandit RA, et al. Indian society of critical care medicine position statement for central venous catheterization and management 2020. Indian J Crit Care Med. 2020:24(1):S6-30.

21. Picardi M, Della Pepa R, Cerchione C, Pugliese N, Mortaruolo C, Trastulli F, Giordano C, Grimaldi F, Zacheo I, Raimondo M, et al. A frontline approach with peripherally inserted versus centrally inserted central venous catheters for remission induction chemotherapy phase of acute myeloid leukemia: a randomized comparison. Clin Lymphoma Myeloma Leuk. 2019;19(4):e184-94

22. Yanbin S, Jun K, Jing W. Management of PICC operation qualification admission for intravenous infusion nurses. Chin J Nurs. 2010;45(9):822-3.

23. Shuang X, Qi W, Qinghua Z. The establishment and application of PICC information management platform. Chin J Nurs. 2020;55(3):379-82.

24. Xuying L, Yongyi $C$, Zhong Y. PICC qualified nurse training model, practice and effect analysis. Chin J Clin Nutr. 2012;20(5):314-5.

25. Junying L, Yan F, Chunhua Y. The effect of specialized PICC catheterization nursing on catheter-related bloodstream infection in patients with lung cancer. Sichuan Med. 2013;34(10):1484-6.

26. Krein SL, Kuhn L, Ratz D, Chopra V. Use of designated nurse PICC teams and CLABSI prevention practices among U.S. Hospitals: a survey-based study. J Patient Saf. 2019;15(4):293-5.

27. Chen P, Wan G, Zhu B. Incidence and risk factors of symptomatic thrombosis related to peripherally inserted central catheter in patients with lung cancer. J Adv Nurs. 2021;77(3):1284-92.

28. Hon K, Bihari S, Holt A, Bersten A, Kulkarni H. Rate of catheter-related bloodstream infections between tunneled central venous catheters versus peripherally inserted central catheters in adult home parenteral nutrition: a meta-analysis. JPEN. 2019;43(1):41-53.

29. Berger R, Messina AF, Chandler NM, Amankwah EK, Shaw PH. Instituting a new central line policy to decrease central line-associated blood stream infection rates during induction therapy in pediatric acute lymphoblastic leukemia patients. J Pediatr Hematol Oncol. 2020:42(7):433-7.

30. Rainey SC, Deshpande G, Boehm H, Camp K, Fehr A, Horack K, Hanson K. Development of a pediatric PICC team under an existing sedation service: a 5-year experience. Clin Med Insight Pediatr. 2019:13:1179556519884040

31. Li X, Ding X, Shi P, Zhu Y, Huang Y, Li Q, Lu J, Li Z, Zhu L. Clinical features and antimicrobial susceptibility profiles of culture-proven neonatal sepsis in a tertiary children's hospital, 2013-2017. Medicine. 2019;98(12): e14686.

32. Campagna S, Gonella S, Berchialla P, Morano G, Rigo C, Zerla PA, Fuzzi R, Corona G, Storto S, Dimonte V, et al. Can peripherally inserted central catheters be safely placed in patients with cancer receiving chemotherapy? A retrospective study of almost 400,000 catheter-days. Oncologist. 2019;24(9):e953-9.

33. LaRusso K, Schaack G, Fung T, McGregor K, Long J, Dumas MP, Attari Z, Yousef Y, Girgis H, Raghunathan R, et al. Should you pick the PICC? Prolonged use of peripherally inserted central venous catheters in children with intestinal failure. J Pediatr Surg. 2019;54(5):999-1004.

34. Longyan $Y$, Weilan $Q$, Jianmei Y. Risk factors and nursing countermeasures of PICC catheter-related complications in neonates. Nurs Pr Res. 2020:37(12):25-7.

35. Elmekkawi A, Maulidi H, MakW, Aziz A, Lee KS. Outcomes of upper extremity versus lower extremity placed peripherally inserted central catheters in a medical-surgical neonatal intensive care unit1. J Neonatal Perinat Med. 2019;12(1):57-63.

36. Yu X, Yue S, Wang M, Cao C, Liao Z, Ding Y, Huang J, Li W. risk factors related to peripherally inserted central venous catheter nonselective removal in neonates. Biomed Res Int. 2018:2018:3769376.

37. Kleidon T, Ullman AJ, Zhang L, Mihala G, Chaseling B, Schoutrop J, Rickard CM. How does your Piccompare? A pilot randomized controlled trial comparing various PICC materials in pediatrics. J Hosp Med. 2018:13(8):517-25.

38. Jin MF, Thompson SM, Comstock AC, Levy ER, Reisenauer CJ, McPhail IR, Takahashi EA. Technical success and safety of peripherally inserted central catheters in the great saphenous and anterior accessory great saphenous veins. J Vasc Access. 2021. https://doi.org/10.1177/1129729821989166.

39. Lee JM, Cho YK, Kim HM, Song MG, Song SY, Yeon JW, Yoon DY, Lee SY. The blind pushing technique for peripherally inserted central catheter placement through brachial vein puncture. J Vasc Surg. 2018;67(3):860-7.

40. Safdar N, Maki DG. Risk of catheter-related bloodstream infection with peripherally inserted central venous catheters used in hospitalized patients. Chest. 2005;128(2):489-95.

41. Zochios V, Umar I, Simpson N, Jones N. Peripherally inserted central catheter (PICC)-related thrombosis in critically ill patients. J Vasc Access. 2014;15(5):329-37.

42. Min J, Jianfang G, Lifen Z. Analysis and prevention of neonatal bloodstream infection associated with peripheral puncture of central venous catheterization. Chin Med Clin. 2020;25(6):1050-2.

43. Litz CN, Tropf JG, Danielson PD, Chandler NM. The idle central venous catheter in the NICU: when should it be removed? J Pediatr Surg. 2018;53(7):1414-6.

44. Yang YC, Mao J. Value of platelet count in the early diagnosis of nosocomial invasive fungal infections in premature infants. Platelets. 2018:29(1):65-70

\section{Publisher's Note}

Springer Nature remains neutral with regard to jurisdictional claims in published maps and institutional affiliations.

Ready to submit your research? Choose BMC and benefit from

- fast, convenient online submission

- thorough peer review by experienced researchers in your field

- rapid publication on acceptance

- support for research data, including large and complex data types

- gold Open Access which fosters wider collaboration and increased citations

- maximum visibility for your research: over 100M website views per year

At $\mathrm{BMC}$, research is always in progress.

Learn more biomedcentral.com/submissions 